\title{
'Gene drive' mosquitoes engineered to fight malaria
}

\section{Mutant mozzies could rapidly spread through wild populations.}

Heidi Ledford \& Ewen Callaway

23 November 2015

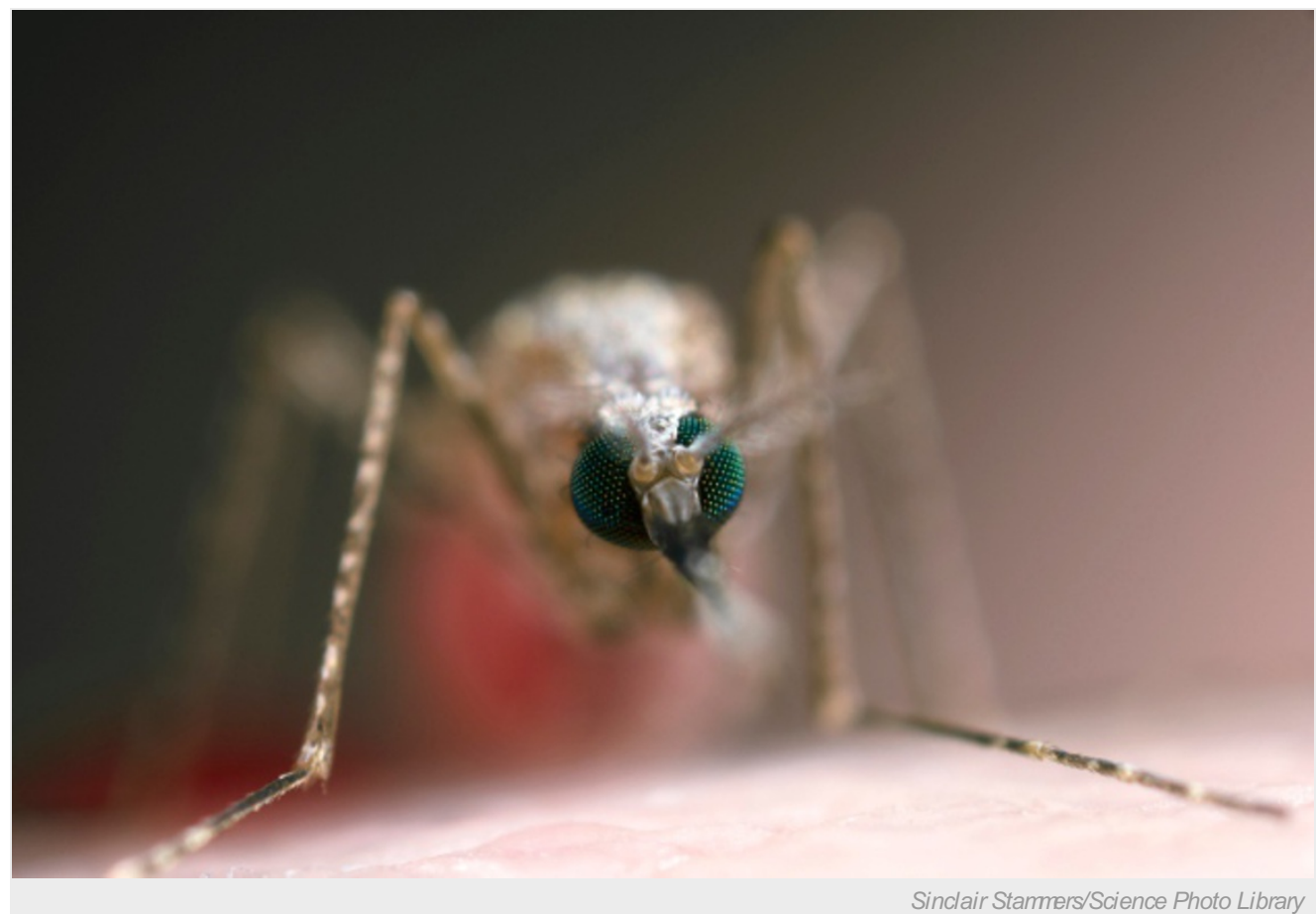

The Anopheles stephensi mosquito can spread the malaria parasite to humans.

Mutant mosquitoes engineered to resist the parasite that causes malaria could wipe out the disease in some regions - for good.

Humans contract malaria from mosquitoes that are infected by parasites from the genus Plasmodium. Previous work had shown that mosquitoes could be engineered to rebuff the parasite $P$. falciparum ${ }^{1}$, but researchers lacked a way to ensure that the resistance genes would spread rapidly through a wild population.

In work published on 23 November in the Proceedings of the National Academy of Sciences, researchers used a controversial method called

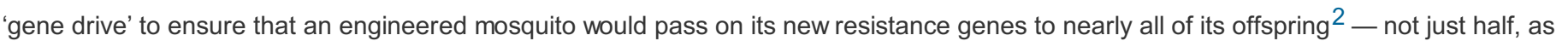
would normally be the case.

The result: a gene that could spread through a wild population like wildfire. 
"This work suggests that we're a hop, skip and jump away from actual gene-drive candidates for eventual release," says Kevin Esvelt, an evolutionary engineer at Harvard University in Cambridge, Massachusetts, who studies gene drive in yeast and nematodes.

For Anthony James, a molecular biologist at the University of California, Irvine, and an author of the paper, such a release would spell the end of a 30-year quest to use mozzie genetics to squash malaria.

James and his laboratory have painstakingly built up the molecular tools to reach this goal. They have worked out techniques for creating transgenic mosquitoes - a notoriously challenging endeavour — and isolated genes that could confer resistance to $P$. falciparum. But James lacked a way to ensure that those genes would take hold in a wild population.

\section{Fast forward}

The concept of engineering a gene drive has been around for about a decade, and James's laboratory had tried to produce them in the past. The process was agonizingly slow.

Then, in January, developmental biologists Ethan Bier and Valentino Gantz at the University of California, San Diego, contacted James with a stunning finding: they had engineered a gene drive in fruit flies, and wondered whether the same system might work in mosquitoes. James jumped at the opportunity to find out.

Bier and Gantz had used a gene-editing system called CRISPR-Cas9 to engineer a gene drive. They inserted genes encoding the components of the system that were designed to insert a specific mutation in their fruit flies. The CRISPR-Cas 9 system then copied that mutation from one chromosome to the other ${ }^{3}$. James used that system in mosquitoes to introduce two genes that his past work showed would cause resistance to the malaria pathogen.

The resulting mosquitoes passed on the modified genes to more than $99 \%$ of their offspring. Although the researchers stopped short of confirming that all the insects were resistant to the parasite, they did show that the offspring expressed the genes.

"It's a very significant development," says Kenneth Oye, a political scientist who studies emerging technologies at the Massachusetts Institute of Technology in Cambridge. "Things are moving rapidly in this field."

Other teams are developing gene drives that could control malaria. A team at Imperial College London has developed a CRISPR-based gene drive in Anopheles gambiae, the mosquito species that transmits malaria in sub-Saharan Africa. The group's gene drive inactivates genes involved in egg production in female mosquitoes, which could be used to reduce mosquito populations, according to team member Austin Burt, an evolutionary geneticist. Their results will be published in Nature Biotechnology next month, Burt says.

Oye notes that such technological advances are outpacing the regulatory and policy discussions that surround the use of gene drive to engineer wild populations. Gene drives are controversial because of the potential that they hold for altering entire ecosystems.

Before testing gene drive in the field, Oye hopes that researchers will study the long-term consequences of the changes, such as their stability and potential to spread to other species, as well as methods to control them. "I'm less worried about malevolence than getting something wrong," he says.

Esvelt says that the US-based researchers made a wise decision in selecting a non-native mosquito species for their experiments. (The team worked with Anopheles stephensi, which is native to the Indian subcontinent.) "Even if they escaped the lab, there'd be no one to mate with and spread the drive," Esvelt says.

James predicts that it will take his team less than a year to prepare mosquitoes that would be suitable for field tests, but he is in no rush to release them. "It's not going to go anywhere until the social science advances to the point where we can handle it," he says. "We're not about to do anything foolish."

Nature | doi:10.1038/nature.2015.18858

\section{References}

1. Isaacs, A. T. et al. PLoS Pathog. 7, e1002017 (2011). 
2. Gantz, V. M. et al. Proc. Natl Acad. Sci. USA http://dx.doi.org/10.1073/pnas.1521077112 (2015).

3. Gantz, V. M. \& Bier, E. Science $348,442-444$ (2015).

Nature ISSN0028-0836 ESSN 1476-4687

\section{SPRINGER NATURE}

C 2019 Macmillan Publishers Limited, part of Springer Nature. All Rights Reserved. partner of AGORA, HINAR, OARE, INASP, OrossRef and COUNIIR 